\title{
SOBRE LAS CIENCIAS DE LA EXPERIENCIA. LOS HERMANOS CRISTIANOS Y LA CONSOLIDACIÓN DEL ORDEN CLÁSICO DEL SABER
}

\author{
Paola Andrea Benavides Gómez* \\ doi:10.11144/Javeriana.uph32-65.hccs
}

\section{RESUMEN}

En el verano de 1995, Santiago Castro Gómez escribió un texto contundente titulado Critica de la Razón Latinoamericana, en este texto el autor siguió los trabajos de Roberto Salazar Ramos, quien hizo parte del grupo de Bogotá encargado de institucionalizar el proyecto de filosofía latinoamericana en Colombia, con el propósito de mostrar el funcionamiento de una serie de discursos que hicieron posible la creación de "lo latinoamericano". Con ello, más que un a priori, la categoría de "Latinoamérica" es definida por Castro-Gómez como el efecto de una serie de discursos al cual se le dotó de una identidad cultural específica. En consecuencia, el autor usa la tradición del historicismo para repensar la historia de la ideas de modo que, en lugar de estudiar la recepción de ideas europeas y medir el grado de acercamiento latinoamericano con respecto a tal andamiaje, su estudio partiera del estudio de las prácticas filosóficas y científicas mismas, como parte "del ejercicio crítico en Colombia". Es, precisamente, en este horizonte abierto por los escritos de Castro Gómez en que se inserta este trabajo.

Palabras clave: historicismo, crítica, práctica científica, orden clásico del saber, sujetos de conocimiento

* Universidad de los Andes, Bogotá, Colombia.

Correo electrónico: pa.benavides39@uniandes.edu.co

Para citar este artículo: Benavides Gómez, P.A. (2015). Sobre las ciencias de la experiencia. Los Hermanos Cristianos y la consolidación del orden clásico del saber. Universitas Philosophica, 32(65), pp. 191-222. ISSN 0120-5323, ISSN en línea: 2346-2426, doi:10.11144/ Javeriana.uph32-65.hccs 


\title{
ON THE SCIENCES OF EXPERIENCE. THE CHRISTIAN BROTHERS AND THE CONSOLIDATION OF THE CLASSICAL ORDER OF KNOWLEDGE.
}

\author{
Paola Andrea Benavides Gómez
}

\begin{abstract}
In the summer of 1995, Santiago Castro-Gómez wrote a convincing text entitled Critique of Latin American Reason, and continued Roberto Salazar-Ramos' work-who also took part in The Group of Bogotá, responsible for institutionalizing the project of Latin American Philosophy in Colombia-in order to show how the creation of "The Latin American" was possible through the operation of a series of discourses. Rather than an a priori, the category of "The Latin American" is defined by CastroGómez as the effect of a series of discourses to which a specific cultural identity was provided. Consequently, the author uses the tradition of historicism to rethink the history of ideas, so that, instead of studying the reception of European ideas and measuring how close to that scaffolding was Latin American thought, its study should begin from the philosophical and scientific practices themselves as a "part of the critical exercise in Colombia". It is precisely within this horizon opened by Castro-Gómez's writings in which this essay is inserted.
\end{abstract}

Key words: historicism, critical, scientific practice, classical order of knowledge, subjects of knowledge 
La Física, la Química, la Biologia y en general todas las ciencias basadas en la experimentación, transportan en sus alas el espiritu, a la contemplación de las obras divinas, y a las naciones, a las más altas cimas del progreso.

Guillermo Bonitto, Discurso inaugural

\section{Introducción}

HACIA LA DÉCADA DE LOS AÑos 70 se institucionalizó en la Universidad Santo Tomás el proyecto de la filosofía latinoamericana, centrado en el estudio y desarrollo de una filosofía auténtica de esta región del mundo, capaz de dar cuenta de los problemas que afrontaron los países de la periferia. Autores claves para este proyecto fueron Ortega y Gasset (1981), Leopoldo Zea (1976), Francisco Miró Quesada (1974) y Enrique Dussel (1980), quienes por distintas vías intentaron avanzar en esa dirección. La liberación de la explotación imperialista y la búsqueda de la identidad latinoamericana se situaron como las directrices que orientaron ese modo de filosofar latinoamericano asumido por el "Grupo de Bogotá". Este proyecto suscitó un haz complejo de reacciones en la comunidad filosófica colombiana, de modo que mientras algunos afirmaban la posibilidad de un filosofar propiamente latinoamericano, entre quienes puede mencionarse a Daniel Herrera (1992), Leonardo Tovar (2001) y Germán Marquínez Argote (1981); otros tantos académicos, como Roberto Salazar Ramos (1995) y Santiago CastroGómez (2010), insistieron en la necesidad de efectuar una revisión crítica del método y los fines del filosofar propuestos por tal proyecto.

Ahora bien, más que reavivar la pregunta por la existencia de una filosofía latinoamericana, este artículo parte del supuesto de que el ejercicio de una filosofía en América Latina debe permitir pensar la realidad histórica, de modo que pueda rastrear el funcionamiento de ciertos discursos desde el criterio de la apropiación de prácticas científicas y teóricas en un momento determinado. En esta oportunidad, el estudio sobre la práctica científica llevada a cabo por la comunidad religiosa de los Hermanos Cristianos, permitirá reconocer el uso dado a conceptos como experiencia, observación y autor para reafirmar la autoridad científica en el medio académico durante la primera mitad del siglo XX.

Las prácticas científicas locales abanderadas por los Hermanos Cristianos se definieron como la continuación de aquél sueño de los hermanos lasallistas de 
ordenar la naturaleza, por el que trabajaron diversos ilustrados criollos. Esta apropiación significó la inserción de la naturaleza colombiana en los marcos de referencia de la ciencia europea, con el objetivo de usar tales conocimientos en el control de las poblaciones y la explotación de recursos naturales que podían ser comercializados. Sin embargo, a pesar de las evidentes coincidencias entre el proyecto criollo y el lasallista, será importante notar la traducción que estos últimos efectuaron del mismo ante la situación económica cambiante de un capitalismo industrializado. Por tal razón, los intereses de la ciencia se redirigen a satisfacer las necesidades propias del proyecto nacionalista adelantado en Colombia hacia la primera mitad del siglo XX.

El Boletín de Ciencias Naturales del Instituto de la Salle, como órgano de divulgación de la Sociedad de Ciencias Naturales del Instituto de la Salle (denominada algunos años después como Sociedad Colombiana de Ciencias Naturales), será el documento que permitirá rastrear la práctica científica lasallista, pues hasta 1930, cuando la sociedad se disolvió, se situó como el espacio privilegiado para consolidar la autoridad científica de la sociedad. Así, un año después de la conformación de la sociedad, hacia febrero de 1913, los socios consiguieron la financiación necesaria de senadores y representantes para publicar el primer órgano de divulgación de la sociedad: El Boletín de Ciencias Naturales del Instituto de La Salle. Tal medio divulgativo les permitió a los socios crear conexiones con naturalistas de diversos países, publicar sus hallazgos y novedades e instruir al público lector en las ciencias naturales. A través de tales procesos, los socios buscaron descifrar el orden de la naturaleza colombiana, de modo que los saberes expertos allí promulgados se usaran como herramientas para controlar y apropiar las riquezas nacionales. Como es notorio, esta iniciativa científica de los lasallistas estuvo inserta en el horizonte ilustrado en el que coincidió el proyecto científico de nombrar la naturaleza, con el proyecto político de apropiar los usos de la misma para evitar la dependencia económica de las importaciones de diversos productos y lograr así un espacio en el mapa geopolítico'.

Estas prácticas científicas lasallistas insertaron en la cosmología cristiana el método experimental centrado en la observación del mundo natural susceptible

1 Sobre la coincidencia entre los proyectos científico y político de los criollos ilustrados veánse los siguientes estudios: Castro-Gómez, 2005; Nieto, 2006 y 2007; Renán Silva, 2002. 
de clasificación y no solo de contemplación. De ahí que se le otorgara un estatuto epistemológico a los viajes, pues implicaba el contacto activo con el mundo natural, la remisión a los textos entonces careció de importancia y el científico debía dirigirse a la naturaleza misma. Ahora bien, este encuentro activo estaba condicionado por unas formas legítimas de acercamiento, razón por la que la taxonomía se situó como el saber moderno por excelencia. Tales prácticas le garantizaron un lugar privilegiado a los socios, pues su misión pedagógica concebía una distancia ilustrada frente al público instruido que no podía definirse como un interlocutor veraz.

Con todo, este artículo estará centrado en tres partes: la primera mostrará las imágenes de ciencia concebidas por la sociedad de lasallistas desde la exposición de los métodos empleados en las sesiones periódicas, en las que se hace evidente la radicalización del ejercicio de observación y una nueva definición de las ciencias experimentales. La segunda hará efectivo el señalamiento de la importancia de los viajes en la práctica científica lasallista y la tipología existente en torno a ellos. Finalmente, en la tercera se reconocerá la particularidad de la imagen del científico y su relación con el público lector del boletín, caracterizado por los socios como lector ignorante y ávido de conocimiento.

\section{Los Hermanos Cristianos. Ciencia y religión}

La Congregación de los Hermanos Cristianos, conocidos también como Hermanos Lasallistas, fue fundada en 1706 por San Juan Bautista de la Salle. Su llegada a Colombia fue posible tras las numerosas peticiones de monseñor Bernardo Herrera Restrepo ante la Santa Sede, para contar con la presencia de la congregación en el país. Como respuesta a los requerimientos de Bernardo Herrera Restrepo, los Hermanos Cristianos arribaron al Estado del Cauca en 1872; allí la estadía fue relativamente corta porque el triunfo liberal garantizó su expulsión de la municipalidad de Popayán. Retornaron al país hacia 1890, cuando de nuevo monseñor Bernardo Herrera solicitó la estadía de la congregación en las ciudades de Medellín, Bogotá, Barranquilla y Honda. A su regreso, la comunidad de Hermanos Cristianos fundó diversas corporaciones educativas como la Escuela Beato Juan Bautista de la Salle y el Colegio San José, la Escuela Apostólica (1893), el Colegio San Bernardo (1893) y el Noviciado de Chapinero (1893). 
Tal como lo afirma Diana Obregón (1992), el interés de introducir en Colombia las escuelas de los Hermanos Cristianos radicó en que al estar orientados hacia la educación técnica y científica, se mostraron como garantes del restablecimiento del orden nacional perdido tras la Guerra de los Mil Días. Desde luego, para el sector conservador y eclesiástico, la presencia de los Hermanos Cristianos se mostraba como una mejor alternativa que la ofrecida por la misión de educadores protestantes alemanes convocada por los liberales radicales. Así, la llegada de la congregación lasallista coincidió con la promulgación de la ley 39 de 1903, en la que se propuso el desarrollo de una educación orientada hacia los saberes técnicos y religiosos, a través de la división de la educación en primaria, secundaria, industrial y profesional. Esta ley, además de consolidar el dominio del Estado sobre la universidad, reafirmó las bases católicas sobres las cuales debía impartirse la educación. Durante estos años de posguerra se restablecieron las actividades de la Universidad Nacional y algunas otras corporaciones del saber que fueron cerradas tras el estallido de la guerra.

De acuerdo con Diana Obregón (1992) y Oscar Saldarriaga (2003), tanto las escuelas normales como los colegios dirigidos por los Hermanos Cristianos adquirieron importancia en la escena nacional como corporaciones del saber de élite que promulgaron la formación científica y técnica, en el marco de un proyecto moderno apropiado en Colombia hacia la primera mitad del siglo XX. En virtud de tales fines modernos, la educación debía formar individuos activos y productivos capaces de responder a la eficacia demandada por el progreso material de la sociedad. De ahí el carácter práctico de la revista y de las cátedras impartidas por el Instituto de La Salle.

A la par de los colegios jesuitas, las instituciones educativas lasallistas contaron con una presencia significativa en la escena educativa del país, al menos en regiones como Bogotá, Barranquilla y Medellín, pues los pocos institutos encargados de la formación de los maestros en el país eran de esta congregación (Saldarriaga \& Saenz, 1997). Como logra notarse en los anuncios divulgados en el diario El Tiempo, la enseñanza de la ciencia significó el estandarte mediante el cual el Instituto garantizaba su carácter moderno y progresista. Este creciente interés por los conocimientos científicos puede interpretarse como respuesta a la ampliación de las funciones del Estado colombiano que, para encontrar materias primas de exportación, necesitaba de conocimientos expertos que le suministrasen un in- 
ventario preciso de las poblaciones y sus recursos naturales. Con todo, este interés científico se mostró acorde con los intereses religiosos que para el período se encargaron de administrar la educación del país, tal como lo ratificó la ley de 1903.

En este marco, es relevante tener un acercamiento al control de la enseñanza en los niveles de primaria, secundaria y estudios técnicos del país, impartido por las comunidades religiosas, especialmente la jesuita y la lasallista. Los planteles privados y públicos quedaron a cargo de los obispos diocesanos, quienes contaban con el respaldo del gobierno para impartir una educación piadosa de la religión. Como parte del plan de restablecimiento del orden nacional desde los parámetros religiosos y técnicos, los Hermanos Cristianos garantizaron la formación de cátedras de ciencias en la formación de docentes, con la ayuda de métodos centrados en la observación atenta de la naturaleza (Saldarriaga \& Saenz, 1997). Con tal propuesta, los colegios de La Salle adquirieron prestigio entre las élites, pues su enseñanza científica se mostró como una práctica moderna, dispuesta al desarrollo del país, y que les garantizaría una serie de distinciones sociales.

Dentro del grupo de religiosos pertenecientes a la congregación lasallista que arribó a Colombia en busca de refugio tras las amenazas europeas suscitadas por la separación entre la Iglesia y el Estado², se encuentra el Hermano Apolinar María, religioso destacado en el desarrollo de la misión pedagógica y científica de la comunidad. De origen francés, el naturalista alsaciano se estableció en Bogotá y asumió la dirección del Instituto de La Salle, así como algunas cátedras de Ciencias Naturales en la Facultad de Medicina. Acompañado de los Hermanos Nicéforo, Cayetano y Ariste, el Hermano Apolinar emprendió la creación tanto de la Sociedad Científica de Ciencias Naturales como del Museo de La Salle, los cuales sirvieron como plataforma para un conjunto de acciones estatales, eclesiásticas e intelectuales.

Los religiosos que acompañaron la misión científica del religioso francés, también se refugiaron en el país tras los decretos laicos promulgados en Europa,

2 "A finales de 1903, el ministro jacobino Emilio Combes, quien busca por todos los medios la separación de la Iglesia y el Estado, consigue de las cámaras francesas la aprobación de la ley que prohíbe a los religiosos vestir de sotana y vivir en comunidad. Frente a esta situación, el hermano busca el exilio voluntario" (López López, 1989, p. 65). 
extranjería que les permitió ratificar su autoridad científica en la sociedad (López López, 1989). Así, Antoine Rouhaire Siauzade, conocido como Hermano Nicéforo María, llegó a Medellín hacia 1909 para impartir clases de ciencias naturales y francés en el Colegio de San José. Una vez fue trasladado a Bogotá hacia 1923, se encargó del estudio de vertebrados en el Instituto de La Salle, acompañando las labores de la sociedad. Por su parte, el Hermano Cayetano se encargó del área de química del Instituto de La Salle, en donde sus investigaciones estuvieron centradas en la posibilidad de lograr combinaciones que dieran lugar a productos utilizables en el área industrial. Como se evidenciará más adelante, el protagonismo del Hermano Cayetano en la sociedad posibilitará la concepción de una ciencia experimental capaz de intervenir en la obra divina. Por último, Maurice Rollot, conocido como el Hermano Ariste, arribó a Colombia hacia 1904, a la región de Caldas, para emprender investigaciones científicas con fósiles. Lo común entre los religiosos mencionados es que, por su formación en ciencias naturales, conciben en la taxonomía la herramienta válida para conocer y clasificar la obra de Dios, de ahí que, una vez vinculados a la Sociedad de Ciencias Naturales, decidieran traducir el modelo ilustrado de ciencia europea en la contingencia natural del país.

En consecuencia, la llegada de la congregación lasallista al país fue posible en un período de posguerra en el que se promovió el control de la Iglesia de la educación primaria, de modo que produjera sujetos productivos para el país. Tras el cese de la Guerra de los Mil Días, Colombia se vio abocada a una serie de búsquedas estratégicas que procuraron restablecer el orden político y económico. Dentro de las medidas asumidas durante el gobierno de Rafael Reyes (19041909), se encuentra la eliminación de impuestos de exportación y el regreso al patrón oro para mitigar la caída de los precios de las mercancías. Así, el programa económico del presidente Reyes incluyó el fortalecimiento de inversiones extranjeras en ferrocarriles, minería y agricultura tropical de exportación (Palacios, 2009, pp. 240-242). A pesar de la importancia económica que tuvo el área cafetera del país, hacia 1906 se emprendió la búsqueda de nuevas materias primas, como el banano, el caucho y el carbón, que le significaran ingresos económicos al país. Con todo, el auge cafetero no cedió y entre 1920 y 1930 la producción de café en el país se duplicó con el consiguiente aumento del empleo, demanda y ahorro. Sin embargo, para lograr el impulso económico se hizo nece- 
saria de la gestión de las poblaciones y los territorios a través del uso de saberes expertos como la geografía y la antropología, de modo que se brindara un diagnóstico estadístico acerca de los recursos y la mano de obra existente en el país, especialmente en las zonas a las que no se había logrado tener una presencia estatal, tales como Putumayo y Chocó.

\section{Clasificar, medir y ordenar}

PARA RASTREAR LAS IMÁgenes de CiENCIA que lograron proponerse a lo largo de la publicación del Boletín, se partirá de la revisión de las actas de las sesiones celebradas por la sociedad que muestran las prácticas que tuvieron lugar durante las reuniones de los socios. También se usarán algunos artículos publicados en el Boletín para dar cuenta del método, el lenguaje y la estandarización de la mirada que fue necesario instaurar para emprender sus investigaciones. Desde luego, los socios resuenan con el modelo de ciencia natural europea centrado en la taxonomía y dispuesto con un leguaje objetivo que podía ser usado de manera indistinta en cualquier región del mundo. Lo que hacen los lasallistas es proveerse de esta tradición y usarla en el estudio y ordenamiento de la naturaleza colombiana; tarea que fue empezada por José Celestino Mutis y Francisco José de Caldas y que, al señalarse como inconclusa, pretendió ser ultimada por la sociedad. La particularidad de los lasallistas radicó en que, aunque promovieron el estudio de la botánica, los artículos y novedades presentados estuvieron del lado de la zoología y la mineralogía, áreas de las ciencias naturales que, además de ser marginales en estudios pasados, se mostraron útiles en el ansia de progreso e industrialización.

Desde el primer ejemplar del Boletín, la sociedad expuso su intención transversal de ordenar la fauna y flora colombiana. Con ello, el imperativo de ordenamiento reguló sus prácticas de fijación de las identidades y diferencias de las especies colombianas en cuadros ordenados. De esta manera, la taxonomía actuó como una herramienta que permitió establecer la continuidad de la naturaleza tras emprender un ejercicio radical de observación. Esta se define como la única vía en la que puede llegarse a un conocimiento objetivo, pues sentidos como el oído, el gusto y el olfato aparecen como poco fiables. La vista, al ser el sentido de la evidencia y de la extensión, permite un análisis de las partes que 
pueden ser usadas en el establecimiento de la clasificación de una especie, aunque el ejercicio científico no se limita a ver, sino a hacerlo sistemáticamente reconociendo variables de colores, formas y superficies medibles ${ }^{3}$. En consecuencia, no todo puede observarse, lo que se observa es la extensión constitutiva de los seres de la naturaleza afectados por cuatro variables: las formas de los elementos, la cantidad de esos elementos, la magnitud relativa de cada uno y la manera en que se distribuyen en el espacio los unos en relación a los otros. Así, cada parte del animal o la planta se mostraba descriptible en la medida en que se vía afectado por las cuatro variables. Por ejemplo, cuando el Hermano Apolinar María se encargó de escribir la sección botánica para establecer un paralelo entre la flora de la sabana y la francesa ${ }^{4}$, al estudiar los órganos sexuales de la planta, consideró suficiente enumerar los estambres y el pistilo, definir la forma que tienen, establecer de acuerdo a qué figura geométrica están repartidos en la flor y mencionar el tamaño que tienen en relación con otros órganos.

En el caso de las aves, los naturalistas debían observar el pico, el plumaje, la forma de las uñas y extremidades. Para ilustrar tal segmentación de la mirada puede referenciarse uno de los artículos publicados por el Hermano Apolinar María en el que expuso la verdadera forma de estudiar un cernícalo: primero se ubica la imagen de la muestra; segundo, se específica el género al que hace parte y los subgéneros que le corresponden; tercero, se realiza la descripción morfológica de las cuatro variables mencionadas tanto del macho como de la hembra. Al final se cita la bibliografía consultada con la que realizó el estudio del ave. Dentro de los estudios se encuentra Augusto von Pelzen, Whitely, Hudson, Chapman, Wetmore y el Magazin de Geografia de Washington'. Los artículos no incluyeron imágenes por las complicaciones y los costos que contraía su publicación en la litografía, apenas se publicaron hacia los últimos años del boletín algunas ilustraciones que acompañaban el estudio enviado por Longino Navas.

3 Una vez Michel Foucault realiza el análisis de la episteme clásica reconoce que el ejercicio de observación que presupone la elaboración de una taxonomía pasa por un proceso de sistematización y regulación de lo que puede ser visto: "ver aquello que, en la riqueza un tanto confusa de la representación, puede ser analizado, reconocido por todos y así recibir un nombre” (Foucault, 2000, p. 134).

4 Véase: Apolinar María, 1913,pp. 9-11.

5 Al respecto, véase: Apolinar María, 1914a, pp. 100-109. 
En ese orden, el método propuesto por los naturalistas lasallistas consistió en deducir progresivamente los caracteres de la muestra: se partía de una especie elegida arbitrariamente o dada de antemano por el azar del encuentro, se la describía por entero de acuerdo con todas sus partes y fijando los valores de las variables; lo mismo se hacía con cada una de las especies encontradas de modo que lograra dibujarse el cuadro general de los parentescos. Con ello, se nombraron cada una de las muestras no a partir de lo que se veía, sino desde las estructuras conocidas por los naturalistas.

Para describir las variables susceptibles de ser observadas, era recurrente que los artículos publicados en el Boletín usaran términos cuantitativos para referir el número y la magnitud; por su parte, las formas y las disposiciones eran descritas con el uso de analogías del cuerpo humano o de figuras geométricas. Tal ejercicio de observación jugó como una manera de estandarizar la mirada de modo que, ante el mismo ejemplar, cada naturalista lograra hacer la misma descripción y, a la inversa, a partir de esta descripción cada naturalista lograra reconocer los individuos pertenecientes a ella. Es importante reiterar que estos métodos científicos no surgieron de la autoría de los socios lasallistas, ellos se encargaron de usar tales herramientas en los estudios locales porque consideraban que era la única manera objetiva de hacer ciencia.

Tales variables, determinantes en el momento de observar, forjaron el campo de lo visible, de manera que las plantas y animales fueron analizados por los cortes visibles de sus órganos y no tanto por su unidad orgánica: son partes y frutos, antes de ser respiración y fluidos internos ${ }^{6}$. Estas descripciones, guiadas bajo las variables de lo que puede ser observado, se convirtieron en "nombres comunes" mediante un ejercicio de fuerza que les permitía adquirir ese valor de verdad. Por tal razón, el proyecto lasallista se insertó en un campo científico en el que se definió un modo de ser de los objetos dentro del saber de la experiencia y desde donde se le otorgó poder teórico a la mirada, de ahí que durante todas las sesiones de la sociedad se dispusiera de al menos dos horas de observación de muestras de acuerdo con las variables mencionadas y la posterior elaboración de la ficha que identificara tales elementos. El seguimiento de dichos condicionamientos definió la veracidad de su discurso y el criterio desde el que se juzgó la producción

6 Véase: Foucault, 2000, p. 137. 
científica de quienes desearon ingresar a la sociedad o participar en el boletín con algunos de sus artículos.

Con todo, esta pretensión de ordenar la naturaleza tuvo como finalidad no solo el ordenamiento de la obra de Dios a través de la vía racional de la cual fue dotado el hombre, sino que, ante todo, y como se ha estudiado en el caso del siglo XVIII con los criollos ilustrados, el conocimiento de la naturaleza permitió la comprensión y explotación de recursos pertenecientes a territorios en los que era débil la presencia estatal. En el caso de los criollos se llevó a cabo la apropiación de saberes locales que, al estar arraigados en tradiciones orales, eran vistos como inferiores y puestos a disposición para ser juzgados por el tribunal de la razón (Castro Gómez, 2005). Una vez los saberes locales eran incluidos en los órdenes de la ciencia europea, se expropiaban de las manos privadas con el fin de centralizarlos y redistribuirlos para beneficio público, en especial cuando ese capital privado tenía alguna utilidad y ganancia económica. Por lo tanto, el Estado asumió la tarea de eliminar la escasez desde la acumulación de riquezas a través del control de los recursos naturales:

El control y la apropiación de la naturaleza debían ser implementados en las colonias mediante la institucionalización de un conjunto de ciencias que le permitieran al Estado reconocer, evaluar, nombrar, clasificar, exportar y comercializar aquellos recursos naturales que consideran útiles para el proyecto de acumulación de riqueza. (Castro Gómez, 2005, p. 205)

En el caso de la sociedad lasallista, esta se encargó de buscar el patrocinio del Estado a cambio de proveerlo de conocimientos útiles respecto a formas efectivas de erradicación de plagas de cultivos y usos de plantas en el tratamiento de enfermedades que, debido a la falta de condiciones higiénicas de vida, acechaban el bienestar de los habitantes; también ofrecieron información respecto a la ubicación de minas susceptibles de explotación, modificación de materias primas con usos industriales y conocimiento geográfico-antropológico de zonas, tales como Arauca y Chocó, cuya colonización se dio de manera parcial. Ahora bien, esta relación entre los naturalistas y los representantes del Estado fue posible desde una doble vía: los naturalistas necesitaban del apoyo estatal para elevar su prestigio y, a la inversa, el Estado los necesitaba para mantener bajo su potestad un inventario de los recursos naturales. De ahí que se financiaran ciertas expediciones a diversas regiones del país para mejorar los registros 
cartográficos de acceso y elaborar un catálogo actualizado de las especies potencialmente explotables del territorio. Por consiguiente, las ciencias naturales se convirtieron así en una herramienta para generar saberes expertos en un juego de poder, con el propósito de lograr la consolidación económica y social del país pero, además, la integración en el mercado internacional desde el modelo imperialista propuesto por Estados Unidos ${ }^{7}$.

En consonancia con tal imagen de ciencia, el museo se consolidó como el espacio legítimo de la experiencia científica. En el caso del Instituto de La Salle, el Museo fue fundado hacia 1904 como un centro de acopio de diversas muestras de la fauna y flora colombiana. Sus colecciones se vieron fortalecidas con la publicación del Boletín, rasgo evidente en los inventarios publicados hacia el final del último número de cada año, pues muchos de los recolectores informales enviaron un número considerable de especies propias de las regiones para que fuesen clasificadas y nombradas por los expertos de la sociedad. Esta facultad de nombrar, puesta en juego en el Museo, significó el ordenamiento de las especies desconocidas bajo el dominio de un lenguaje científico. Para nombrar era necesario tomar distancia del lenguaje cotidiano, plagado de ambigüedades e ignorancia, y traducir los ejemplares con palabras "neutrales" que permitieran describir el mundo con objetividad. Así, el naturalista al nombrar el objeto lo descubría, razón por la que no se les daba crédito a los aficionados encargados de la recolección. Para evitar las confusiones en el establecimiento de especies nuevas, se decretó, hacia 1928 en el Congreso Internacional de Zoología reunido en Budapest ${ }^{8}$, que cuando cualquier autor describiese una especie nueva era necesario que lo hiciera de manera explícita, en el caso de copiar un nombre genérico era necesario añadir el número y el año de publicación de la denominación copiada. Tales recomendaciones fueron acogidas durante los últimos años de publicación del Boletín para nombrar especies encontradas por los socios. Claro está que este acto de nombrar, al que se hace referencia, necesitaba contar

7 Es Camilo Quintero (2012, p. 4) quien, al abordar las relaciones imperialistas entre Colombia y Estados Unidos, afirma que resulta pertinente pensar el imperialismo desde una perspectiva informal, especialmente cuando se analizan las relaciones científicas sostenidas con los países de América Latina. De esta manera, aunque no funcionó como el imperialismo europeo de los siglos XVI al XIX, las relaciones de poder que se cristalizan implican una expansión similar. 
con la aprobación de las autoridades extranjeras, motivo por el que ante cualquier rastro de duda se enviaban las correspondientes evidencias a especialistas de Estados Unidos y España para que fuesen ellos los encargados de decretar el carácter novedoso de la especie.

Este modelo de objetividad y universalidad proveído por las ciencias naturales coexistió, tras la aparición del Hermano Cayetano como un líder más de la sociedad, con la imagen experimental ofrecida por la química. Esto no quiere decir que la taxonomía cediera su lugar ante la experimentación de laboratorio ofrecida por la química, sino que, por el contrario, se ubicó en el mismo plano útil en el proyecto nacionalista. Así, hacia 1916, en las actas de la sociedad y los discursos leídos durante las actividades, se usaron con mayor amplitud el término experimental para dar cuenta de sus estudios enfocados hacia el progreso. Tal es el caso del discurso leído por el socio Guillermo Bonitto en el acta del 28 de agosto de 1916, quien afirmó que el carácter experimental de las ciencias contribuía al progreso de las naciones porque no se limitaba a la contemplación de las obras divinas ${ }^{9}$. En esta imagen de ciencia resultan importantes los experimentos del Hermano Cayetano en su laboratorio ubicado en el Instituto de La Salle, en donde él, por ejemplo, fabricó cemento y destiló petróleo ${ }^{10}$. También son relevantes los artículos expuestos en la sección de mineralogía en los que se ofrecen estudios que evidencian la utilidad de elementos como el manganeso en la industria siderúrgica ${ }^{11}$.

De acuerdo con lo anterior, las prácticas científicas de la sociedad coexistieron bajo el nombre de ciencias experimentales encargadas de observar, clasificar e intervenir en la obra de Dios. En esa medida, los espacios legítimos de las prácticas serían el museo y el laboratorio, en donde los sabios naturalistas y los hombres experimentales realizarían sus investigaciones. No obstante, esta imagen de ciencia sería impensable sin los viajes emprendidos por los socios en la realización del proyecto lasallista, razón por la cual el siguiente apartado mostrará la tipología de excursiones presentadas en el Boletín.

9 Véase: Bonitto, 1916, pp. 113-117.

10 Véase: Cadavid, 1918, pp. 41-46.

$11 \mathrm{Al}$ respecto, el primer número del Boletín publicó un estudio sobre el manganeso que contó al menos con cinco entregas periódicas. 
CON EL FIN DE COMPRENDER LAS PRÁCTICAS LOCALES de los lasallistas es necesario reconocer la importancia que adquirieron los viajes en su proyecto científico, pues estos sirvieron para crear un inventario exhaustivo de especies que lograran ser transformadas en valor de cambio. La razón de los viajes emprendidos por la sociedad ya no radicó en el descubrimiento de tierras vírgenes, como sucedió siglos antes durante las diversas expediciones patrocinadas por el Imperio Español, sino en el hallazgo de materias primas que al ser usadas en la agricultura, la industria o la medicina contribuyeran en el progreso del país. También era importante tener en cuenta ciertos datos antropológicos para caracterizar la disponibilidad de la mano de obra en caso de existir alguna mina disponible para su explotación. De esta manera, se evitaría la dependencia económica del país con la importación de productos.

El presente apartado evidenciará dos tipos de viajes que dieron sentido a las actividades de la Sociedad de Ciencias Naturales del Instituto de La Salle: el primero se refiere a las excursiones emprendidas por los socios para llevar a cabo la caza y recolección de algunas muestras animales, vegetales y minerales; el segundo tiene que ver con las expediciones de colonización y evangelización de territorios nacionales alejados. Ambas clases de viajes les permitieron a los socios enriquecer sus colecciones personales pero, ante todo, crear un inventario de las riquezas naturales de las regiones visitadas para posibilitar su posterior explotación. Por esta razón, se elaboraron minuciosos mapas y descripciones de las particularidades de la fauna y flora presentes en los territorios, como una enmienda de los errores ofrecidos en las excursiones pasadas. En este punto fue importante la vinculación de Ricardo Lleras Codazzi como integrante de la entonces nueva Sociedad Colombiana de Ciencias Naturales.

El Boletín inauguró su lanzamiento con la sección llamada "Excursión científica", en la que los autores publicaron los diarios de sus viajes de cacería hacia los diversos pueblos de Cundinamarca. En este mismo ejemplar se publicó el diario de viaje de cacería emprendido por diez socios que salieron hacia Guasca el 12 de enero de 1913. La narración se encargó de describir los paisajes que lograron contemplar en su trasegar, así como las aves y plantas recolectados. Como los insectos no salían de los escondrijos fue necesario remover piedras y 
troncos para hallarlos, curiosidad científica que sería propia del naturalista colombiano. Dentro de los lugares visitados se encontraron el boquerón de Sopó, las minas carboníferas del Santuario, las fuentes termales y el páramo de Sumapaz. En esta misma línea, Gabriel Abadía (1913, pp. 58-62) narró su viaje hacia el oriente de Cundinamarca en el que recolectó un número importante de muestras de lepidópteros cuyo listado presentó en el artículo.

Como puede notarse, los viajes se constituyeron en actividades necesarias para conformar las colecciones del Museo de La Salle y llevar las muestras que serían observadas durante las sesiones de la Sociedad. El viaje se consolidó como una forma de conocimiento genuino, pues estaba basado en el único sentido fiable: la vista. Como se dijo con anterioridad, la supremacía de la mirada frente a los demás sentidos, le dio un carácter de objetividad a la ciencia, pues la mirada que lanzaba el viajero estaba condicionada por las variables que debían incluirse en la observación de la naturaleza. El testimonio de vista que lograban establecer los viajeros, a la luz de la estandarización de la mirada, se situó como la forma legítima de decir con sentido la verdad de la naturaleza, por lo que se desacreditaron los testimonios de oídas emitidos por los actores locales.

Ante tal preeminencia del testimonio objetivo de la vista, el Hermano Apolinar María narró (1914b, pp. 14-17) la excursión que, junto al Hermano Estanislao José, emprendió hacia el Páramo de Choachí. El diario de viaje expuso las actividades de recolección que realizaron los viajeros una vez llegaron a su destino, así como los apuntes que tras cada observación lograban incluir en sus libretas. Según el Hermano Apolinar, el propósito del viaje fue "recoger datos sobre entomología y botánica” para descubrir nuevas especies de mariposas; de esta manera, como algunas de las muestras no cumplieron con las características de las especies conocidas, decidieron llamarlas, en honor al entomologista, Colias Dimera Var Fassil. Tal domesticación de la naturaleza, desde el acto de nombrar, sugiere un ejercicio de poder desde donde se sobrepone la visión del mundo del evangelizador frente a la del nativo:

El derecho del señor a dar nombres llega tan lejos que deberíamos permitirnos el concebir también el origen del lenguaje como una exteriorización de poder de los que dominan: dicen "esto es esto y aquello", imprimen a cada cosa y a cada acontecimiento el sello de un sonido y con esto se lo apropian, por así decirlo. (Nietzsche, 2009, p. 38) 
Durante los días de viaje, el Hermano Apolinar, entre otras cosas, consignó en su diario la observación que realizaron de un huevo de mariposa encontrado en la hoja de un trébol y la posterior revisión de las taxonomías existentes en sus libros de manera que se encontrara la especie a la que pertenecía. Los viajes se sitúan, de nuevo, como espacios en los que despliega la práctica científica del ordenamiento taxonómico, a través de la observación de variables de la naturaleza.

A la par de las excursiones científicas, los lasallistas promovieron la realización de viajes de evangelización a los habitantes de los territorios alejados del país, tales como Chocó y Caquetá. Dichos viajes contaron con la presencia de varios representantes de los estamentos oficiales del país (cartógrafos, religiosos y militares) que procuraron mantener el dominio de los territorios y domesticar a los nativos de la región. Por esta razón, se elaboraron mapeos poblacionales que examinaron las características físicas y morales de los nativos y establecieron una relación determinante entre su comportamiento y las condiciones geográficas de su asentamiento. También se elaboraron nuevos mapas que contaron con mayor precisión de las dimensiones geográficas y naturales de algunas regiones cuyas mediciones, aunque se referenciaron en estudios antiguos, eran imprecisas. Por ejemplo, hacia septiembre de 1913 se publicaron los hallazgos que L.M. Ferreira (1913a, pp. 115-117; 1913b, pp. 129-132) obtuvo tras su excursión a Chocó. De manera específica, se elaboró una reseña sobre las fuentes de platino que logró encontrar y el uso de monitores como el mejor método de extracción por el bajo costo y el rendimiento que obtenía en labores a gran escala, en contraste con el buceo empleado por los habitantes, que se presentó como un método poco eficaz.

La sección antropológica sería la encargada de dar cuenta de las excursiones evangelizadoras de los lasallistas. El presbítero H. Rochereau inauguró esta sección con la publicación de los diarios de viaje que, a manera de Las Crónicas de Indias, tuvo la función de narrar los paisajes de la travesía y la descripción objetiva de los comportamientos de los nativos del lugar. La misión evangelizadora hacia el Cocuy fue alentada por el Obispo y el gobernador General Rafael Valencia, quienes nombraron al padre Rochereau, al Dr. Monsalve y al subteniente Néstor Parra como líderes eclesiásticos y militares de la misma. Este viaje tenía el cometido de cristianizar a los indios Tunebos para tener acceso a las riquezas de su territorio y lograr un intercambio mercantil con los jefes de la tribu. En palabras del mismo Rochereau (1914a): “deseoso, y también el cura de Toledo, de es- 
tudiar el modo como se podrían civilizar estos Tunebos, habíamos determinado un viaje a esas regiones" (p. 97). Cada uno de los integrantes del grupo de "civilizadores" tuvo una función específica: el subteniente Néstor Parra, como autoridad militar, debía hacer un breve estudio topográfico de la región y estudiar las condiciones de posibilidad para que se diera una marcha de tropas por el Sarare. Por su parte, Fernando Monsalve y sus jóvenes acompañantes (Ignacio Mora, Zenón Contreras y tres peones) debían encargarse de la descripción de las costumbres y de las riquezas naturales del territorio. Lo curioso es que una vez llegaron al lugar, los misioneros notaron la dificultad de trazar la topografía del mismo, en virtud de la "falsedad" de los mapas con los que se contaba.

En la siguiente entrega del viaje de cristianización, Rochereau (1914b, pp. 135141) describió las relaciones de los indios con los blancos desde el comercio de cera, otoba, caucho, mochilas y la compra o intercambio de sal, ruanas y cuchillos. Al parecer, los indios se mostraban violentos con los blancos porque habían sido robados y engañados. También se refieren a algunas de las características físicas de los nativos: la fealdad, la mansedad de carácter, los adornos usados y la alimentación a base de maíz, plátano, yuca, ñame y los productos de cacería. Al escribir estas notas, Rochereau se define a sí mismo como la plataforma neutral que se limita a describir sus observaciones y como un misionero que, tras prestar atención al estado de barbarie de los Tunebos, siente la necesidad de someterlos en nombre de la verdad del cristianismo. Por tal razón, Rochereau (1914c, pp. 195-197) elaboró un listado con el vocabulario usado por los indígenas con su respectiva traducción española, para hacer más efectiva la comunicación y el intercambio mercantil. El extracto de tal listado se divulgó en el Boletín de manera pormenorizada.

Dos años después de la misión evangelizadora de los tunebos efectuada en 1914, Roberto Velásquez (1916, pp. 131-137) envió a la sociedad un estudio sobre los indígenas Chamíes que habitaban en Manizales. El artículo definió las costumbres de la tribu como extrañas y extravagantes, debido a que, aunque conocían sobre el Dios cristiano enseñado por los misioneros, conservaban un dualismo religioso al estilo persa. Sin duda alguna, el autor afirmaba que la misión de Rochereau le sirvió como inspiración para tener un acercamiento a los Chamíes. Claro está que la cristianización de los Tunebos no cesó tras el viaje de la comisión liderada, entre otros, por Rochereau; por lo que Marco Cristancho 
Leal se encargaría de dar continuación con las entregas sobre las experiencias surgida tras su convivencia con las tribus, lo que le permitió concluir que los indígenas conocían la distinción entre el bien y el mal, razón por la que practicaban rituales inmorales a los que ninguno de los expedicionarios logró ingresar, al respecto, menciona la realización de sacrificios humanos ${ }^{12}$. Tal como lo haría un cronista de Indias, el socio Cristancho Leal aseveró que los tunebos eran perezosos, fumadores y alcohólicos, aunque con un gran sentido de hospitalidad.

La misión evangelizadora a la que se hizo referencia continuó diez años después del viaje emprendido por el padre Rochereau. Él mismo, hacia 1924, lideró la travesía hacia el Alto Arauca ${ }^{13}$. Así, luego de notar el abandono al que estaban sometidos los indígenas de Sarare, Rafael Afanador decidió enviar una expedición para convertir y proteger a las tribus, el artículo publicado en el Boletín afirma: "las condiciones especiales del Sarare exigen que la colonización proceda a la catequización de los indígenas" (Rochereau, 1924a, p. 123). Sin embargo, como los habitantes de la tribu se mostraban adversos a la presencia de "blancos" se pensó que la comunidad de los Trapenses ${ }^{14}$ sería idónea para adelantar la misión. Para el momento en que se planeó el viaje, esta comunidad no se encontraba en Colombia, razón por la que se planeó su llegada desde Brasil y se dispusieron ciertas hectáreas de tierra en las que podrán realizar su labor. La narración del padre Rochereau empieza con un recuento de los preparativos del viaje respecto al abastecimiento de comida. En las entregas enviadas al Boletín solo se publicaron los rasgos pictóricos del viaje, pues el informe detallado era exclusivo de la Unidad Católica de Pamplona y las especificidades etnográficas habían sido adquiridas por la Sociedad de los Americanistas de París. En virtud de tales acuerdos, las descripciones consignadas en el Boletín se limitaron a exponer la acción contemplativa del trayecto del viaje y la intención del viajero de querer descifrar el misterio de la naturaleza tras un ejercicio reflexivo. Sobre este asunto se dice:

12 Véase: Cristancho, 1918, pp. 25-32.

13 Véase, para la primera entrega del informe: Rochereau, 1924a, pp. 123-128; para la segunda: Rochereau, 1924b, pp. 161-163.

14 Esta comunidad de misioneros proveniente de Brasil se encargó de misiones cristianas en zonas selváticas. 
Regresó a fines de Diciembre con un mapa de la región, un plano al 1/8000 de la concesión que pediremos al gobierno nacional, y con un estudio detallado de la región, naturaleza del terreno, fauna, flora, caminos, fundaciones, densidad de la población indígena, usos y costumbres de los indios. El informe detallado se está publicando por la Unidad Católica de Pamplona y la parte etnográfica por la Sociedad de los Americanistas de París. Reservaremos para la Revista la relación pintoresca de nuestro viaje. (Rochereau, 1924a, p. 125)

Ahora bien, aunque la exclusividad fue adquirida por distintas organizaciones, las diversas entregas del informe incluyeron descripciones sobre el carácter de los nativos respecto a su astucia y aparente sumisión. Tales imágenes tenían lugar dentro del estereotipo del buen salvaje que, pese a su ignorancia y barbarie, contaba con la gracia de Dios para ser salvo ${ }^{15}$.

Si bien la función evangelizadora de los viajes era explícita, es cierto que tales travesías permitieron el conocimiento de zonas que podrían potenciar el sector agrícola e industrial del país. Por este motivo, se renovaron los mapas que se tenían de las zonas y se describieron plantas que, por su uso medicinal ${ }^{16}$, devendrían en benéficos hallazgos para los naturalistas. Con tal propósito, A. M. Barriga, profesor de química de la Universidad de Bogotá, emprendió una expedición hacia Putumayo y Caquetá en la cual logró descubrir el yagé. El informe presentado al Boletín dio cuenta de la preparación y los efectos de la bebida en los sujetos que la consumían sin causar envenenamiento, sino apenas una anestesia general. Esta particularidad del yagé haría de la bebida un elemento importante en el futuro, como medicamento para tratar el dolor de diversos tejidos sin modificar funciones importantes. Respecto a la clasificación botánica de la planta se afirmó que, debido a la muerte de Santiago Cortés, debían enviar muestras a Europa para que se encargaran de catalogarla. Este gesto evidencia de forma clara las relaciones dependientes que la sociedad sostenía con el resto del mundo, ante la imposibilidad de realizar ellos mismos investigaciones autorizadas.

15 Esta descripción tiene lugar en la tercera entrega del diario de viaje. Véase: Rochereau, 1925, pp. 37-39.

16 Sobre la ilustración y los remedios del imperio véase: Nieto, 2006. 
Los últimos informes publicados por el Boletín se refirieron a las participaciones de Ricardo Lleras Codazzi y José Vallejo en las expediciones hacia Payandé (Tolima) y Chocó, respectivamente. De un lado, la sección de geología divulgó las apreciaciones del autor sobre las propiedades mineralógicas del territorio que podían ser explotadas; por otro lado, José Vallejo, a modo de Crónica de Indias, presentó con detalle las características del clima de la región y su influencia en el comportamiento de los nativos, también elaboró un recuento de las misiones emprendidas hacia la región y que fracasaron debido a las condiciones agrestes del territorio. Esta narración se inserta en el horizonte ilustrado en el que, como bien lo demuestra Mauricio Nieto (2006), se discutió ampliamente sobre el imperio del clima en el comportamiento de los hombres.

Hasta el momento se procuró un acercamiento a los viajes que hicieron parte de la práctica científica de la Sociedad Colombiana de Ciencias Naturales, como espacios en los que se lograba lanzar una mirada a la naturaleza desde el establecimiento de variables que permitieron su clasificación. Además, se concibieron los viajes como formas de conocimiento legítimo que posibilitaron el levantamiento de cartografías de los territorios que se re colonizaron y de los sujetos que los habitaban. En lo que sigue será relevante abordar la imagen del científico que se sobreviene del proyecto científico mencionado y la relación que desde tal imagen se erigió con los lectores.

\section{El olor de la naftalina}

HACIA 1915 SE PUBliCó EN EL Boletín un artículo titulado: "L'intermédiaire des bombyculteurs et entomologistes", como una reflexión sobre la función del naturalista en tanto sabio que observa la obra de Dios. Estas personalidades excepcionales encarnadas por los naturalistas debían mostrarse acordes con el modelo de hombres blancos y letrados, superioridad que se garantizó por su cercanía con Europa; precisamente, al encarnar estos rasgos, el Hermano Apolinar fue denominado como "lumbrera" de la ciencia colombiana. La imagen puesta en juego requirió la especialización de los científicos que, al ser reconocidos como tales, necesitaban cumplir una serie de características que entablaran cierta distancia social y epistémica con el vulgo. Tal distanciamiento se mostró perfectamente compatible con el deseo de "pedagogizar" al lector ignorante para expandir 
la curiosidad científica, pues el ejercicio paternalista supuso el reconocimiento de diferenciación frente a la alteridad a través de signos visibles, como botones con insignias, o de formas no exteriores, desde la aceptación de la autoridad epistemológica de su experticia.

Este sujeto de conocimiento que pretendió erigir la sociedad debía contar con ciertas virtudes como: la agudeza del sentido de la vista, la paciencia, la imaginación y el temple para llevar a cabo su labor. Sentado en su escritorio con la lupa siempre asida en la mano, con olor a naftalina y gibado por su quietud, este naturalista rememoraba las antiguas imágenes de los sabios ilustrados que, tras pasar horas en sus mesas, pensaban las relaciones entre los seres bajo la forma del orden y la medida. Por tal razón, la formación de vastas y completas colecciones se situó como el propósito de su existencia, de ahí que el naturalista sostuviera una relación casi onírica con la misma:

Respira con delicias el olor acre de la naftalina, perfume que si hace toser a los profanos tiene para él toda la fragancia de la violeta o del jazmín. En su derredor, encima de los muebles, sobre las mesas, cuerpecitos de insectos con élitros anubarrados, semejan al reflejar la luz, centelleantes alhajas

(...) De improvisto todo se desvanece, las malvadas mariposas huyeron. (Gaell, 1915, p. 29)

En virtud de tal construcción de la imagen del científico, el socio E. Lora escribió, algunos años después, que la definición más apropiada para los científicos era la de "genio". Esta categoría reunía las mismas virtudes propuestas por Gaell, pero además de ser un sabio desbordado en su colección, el genio, al tener un halo de superioridad y excepcionalidad divina, se definió como un líder mesiánico encargado de liberar a los hombres de la prisión labrada por la ignorancia. Al respecto E. Lora (1917) afirma:

en ninguno de los seres de la creación se refleja tan visiblemente la imagen de Dios como en el genio; si los rayos del sol, concentrándose en el foco de un lente, nos dan la imagen del astro, los rayos de la inteligencia, emanaciones de la divina, al concentrarse en el cerebro de un hombre, nos dan la imagen de Dios; los genios son como focos luminosos que la Providencia envía delante de los pueblos, para que los conduzcan de los desiertos de la ignorancia a la tierra prometida de la civilización. (p. 14) 
A modo platónico ${ }^{17}$, el genio tendría la tarea de permitirles a los prisioneros el conocimiento de lo verdaderamente real. En el contexto colombiano, esta tarea les permitió a los genios instruir a los estudiantes y lectores del Boletín para que dejaran los lugares comunes del vulgo, de modo que especializaran su conocimiento de la naturaleza al usar el lenguaje científico y, así, inaugurasen una manera legítima de relacionarse con el mundo.

Ahora bien, como se dijo antes, no sería lícito afirmar la univocidad de la imagen del científico en el Boletín; por el contrario, los socios no solo definieron al científico como sabio, sino también como hombre de laboratorio capaz de modificar la composición de la naturaleza mineral, de modo que lograra ser usada industrialmente. Al respecto, Julio Manrique, expresidente de la Sociedad, afirmó en un discurso pronunciado en la conmemoración del centenario de la Batalla de Boyacá:

El profesor del Instituto ha llegado a inspirar a sus discípulos el amor a esta ciencia, dejándolos trabajar en el laboratorio, único lugar donde es posible comprender algo de los misterios del análisis y de la síntesis. De cada análisis hecho por el profesor o por los discípulos, quedan en receptáculos apropiados producidos por los diferentes reactivos, lo que da un magnífico resultado pedagógico. (Manrique, 1919, p. 87)

Tal imagen del sabio y del hombre de laboratorio manifiesta una relación de estos sujetos de conocimiento con el público lector. Por esta razón, el siguiente apartado señalará diversas estrategias mediante las que se buscó ejercer la autoridad científica desde la instrucción del lector en las formas legítimas de ciencia.

\section{Los lectores del Boletín}

Como lo afirma Olga Restrepo (1996), las publicaciones científicas forjan un auditorio ideal a quien dirigir sus artículos y cuyas lecturas pueden influir en las publicaciones de la revista. Esta relación circular implica una mutualidad entre la revista y el público hacia el cual se dirige, sin que alguna de las dos instan-

17 Por muchos es conocida la alegoría de la caverna, prisioneros atados en una caverna de tal manera que sólo pueden ver las sombras de los artefactos proyectados por el fuego que está a sus espaldas, que alguna vez son liberados para que contemplen lo real y que, tras un proceso ascendente, son obligados a bajar para enseñar y liberar a sus compañeros. 
cias se mantenga pasiva ante la otra. Así, el Boletín de Ciencias Naturales del Instituto de La Salle, como otras tantas revistas, se dirigió a un tipo de lectores aficionados y expertos hacia los cuales extendió su autoridad científica. El presente apartado caracterizará el variado auditorio del Boletín, así como las estrategias retóricas y discursivas empleadas por los socios para "pedagogizar" al lector.

Sería erróneo afirmar el carácter homogéneo del público al que se dirige el Boletín, por tal motivo, se caracterizará dicho auditorio a partir de dos tipos de lectores sugeridos en las publicaciones: el primero se refiere a los expertos y sujetos que contaban con cierta visibilidad en la escena política nacional; el segundo tipo incluye a los aficionados de las ciencias naturales que, aunque carecían de formación especializada, eran sujetos curiosos y receptivos del saber, cuyas formas de pensamiento estaban dispuestas a ser modificadas luego de recibir una apropiada instrucción.

Tras una revisión de las actas periódicas de las reuniones de la sociedad y de las cartas publicadas en el Boletín, puede inferirse que los socios estaban interesados en mantener como lectores activos a los instructores públicos, políticos, hombres con cargos públicos en el país, profesores del Instituto de La Salle, profesores del Colegio San Bartolomé y naturalistas como Longino Navas, Santiago Cortés y Emilio Cuervo. Estos actores tienen en común la autoridad política o científica emanada de sus estudios y del reconocimiento nacional con el que contaban. En esa medida, los artículos publicados se encargaban de mostrar las novedades en las diversas áreas de las ciencias naturales como la ornitología, zoología, botánica y antropología, de tal manera que estos lectores enriquecieran al boletín con enmiendas, comentarios y estudios de su autoría.

La lectura de la correspondencia recibida durante el inicio de las sesiones de la sociedad, muestra el asombro o la inconformidad de los lectores expertos con ciertos artículos divulgados en el boletín; así, ellos se encargaban de redactar extensas cartas en las que, de manera puntual, señalaban los argumentos contradictorios o las evidencias que podían sustentar con mayor validez el problema abordado. Por ejemplo, hacia 1915, F.R de la Torre y Thorne (1915, pp. 101-112), secretario de la Brooklyn Entomological Society, escribió una carta al Hermano Apolinar en la que incluyó un comentario al artículo publicado por él en el que daba algunas indicaciones a los jóvenes naturalistas para efectuar la recolección de muestras animales y vegetales. Según el secretario, las indicaciones del Hermano Apolinar 
deberían complementarse con instrucciones sobre la colección de hemípteros, razón por la cual adjuntó las indicaciones para cazarlos en diversas regiones y espacios. Tal correspondencia indica la circularidad de las relaciones entre el Boletín y sus lectores expertos; después de todo, la enmienda fue publicada en el Boletín con una extensión de once páginas y un comentario del Hermano Apolinar en el que admite la importancia de la rectificación efectuada. Con ello, la supuesta pasividad de los lectores queda objetada desde el continuo establecimiento de correspondencia escrita entre los socios y sus lectores expertos.

Esta relación entre colegas se ve ausente en el trato dado a los lectores aficionados quienes, a pesar de su entusiasmo, necesitaron de la instrucción del Boletín para que puedan comprender el carácter práctico de los artículos. Más allá de discutir sobre las novedades en ciencias naturales, la comunicación de los socios con este tipo de lectores fue usada para enriquecer las colecciones de los museos y efectuar las observaciones en las sesiones pertinentes. Los estudiantes del Instituto de La Salle, los recolectores anónimos diseminados en varias regiones del país, especialmente en Cundinamarca, Boyacá, Antioquia y Santander; así como los hombres de letras que se dedicaban a la cacería y estudiantes de colegios e instituciones técnicas, eran considerados como lectores amateur a quienes debía ensenárseles los procesos para realizar una verdadera práctica científica. Dentro de este grupo también podría situarse a los industriales que, sin tener el conocimiento necesario para comprender las minucias científicas, contaban con los medios técnicos y económicos para llevar a cabo la explotación mineral. Después de todo, la misión del Boletín, desde un inicio, estuvo centrada en proveer las herramientas para que los industriales nacionales lograran la explotación del suelo. Sin embargo, a pesar de su importancia, muchos de los industriales requerían de la guía del Boletín para llevar a cabo sus labores.

Con todo, los socios consideraron importante dirigir sus investigaciones a los jóvenes porque poseían un ánimo influenciable y enérgico. En este punto es necesario recordar que para la primera mitad del siglo XX, según lo muestra Ricardo Arias (2011), las tasas de analfabetismo en Colombia ascendían al setenta por ciento de la población mayor de 14 años y la mayoría de estudiantes estaba matriculados en el sector público, motivo por el cual, los socios dirigieron sus escritos hacia los estudiantes de sus instituciones fundadas en diversas regiones del país, así como a los alumnos que hacían parte del Colegio San Bartolomé en Bogotá. 
El Hermano Apolinar María fue el encargado de escribir diversos artículos en los que se ofreció aquél "apoyo pedagógico" a los jóvenes lectores, cuya función sería incentivar el ejercicio de recolección de muestras y su correcta clasificación. En palabras del Hermano Apolinar (1914c): "Para ayudar a nuestros jóvenes colegas en el estudio y recolección de las principales especies de minerales que constituyen el suelo patrio, principiamos hoy una serie de artículos sobre dichas especies" (p. 125). Tal como se afirma en una de las conferencias dadas a los alumnos de la primera división del Instituto de La Salle, parte de la función del Boletín era la instrucción a gente no iniciada en los estudios de ciencias naturales ${ }^{18}$.

La primera instrucción al lector aficionado ofrecida en el Boletín estuvo centrada en la recolección de minerales. De cada una de las formas de recolección se enunciaron solo los aspectos esenciales, dejando de lado las indicaciones "difíciles" para jóvenes principiantes. Los minerales que fueron descritos en el artículo hacían parte de la colección mineralógica con la que contaba el museo, para su clasificación se usó el estudio de Alberto de Lapparent. De manera general, las instrucciones comenzaban con la descripción del nombre científico; luego se enumeraban ciertas características físicas respecto a forma, color y tamaño (variables que debían segmentar la mirada); enseguida, se identificaba la región del país en la que fue encontrado, así como las variedades existentes y las utilidades industriales del mismo. Al respecto, el Hermano Apolinar afirmó que los jóvenes debían recoger "muestras inalteradas" del seno de la roca sana y no del suelo. Sus palabras fueron: "Cuando uno quiere formar una colección verdaderamente científica y que quiere verificar canjes con colegas de otras regiones de la República, claro está que debe tratar de recoger muestras en número bastante crecido para poder enriquecer su propio caudal” (Apolinar María, 1924, p. 64). Cada muestra debía contar con una información que permitiera catalogar la colección privada, y los datos que debía incluir el rótulo eran la fecha y lugar de la recolección, de modo que lograra contar con varios ejemplares de una misma clase.

Ahora bien, las instrucciones dadas por el Hermano Apolinar incluyeron indicaciones necesarias en las áreas de geología y paleontología. En este caso, el joven naturalista debía hacer sus recolecciones de las rocas ígneas y sedimentarias e incluir un rótulo en el que incluyera el lugar, fecha, espesor, dirección e

18 Un extracto publicado de la conferencia puede consultarse en: Apolinar María, 1924, pp. 36-39. 
inclinación de las capas y utilidades de las muestras. En cuanto a la botánica, el Hermano Apolinar consideró que la planta debía recogerse en un estado de integridad, en caso de pertenecer a una especie herbácea y de tamaño mediano el ejemplar debía tomarse entero, es decir, con raíces, hojas, flores, y si fuere posible con frutos. Si la muestra resultaba demasiado grande, y por su extensión no tuviera lugar en la hoja del herbario, era necesario doblegarla cuantas veces fuse necesario; por su parte, si se tratara de una planta muy grande o de un árbol, el joven naturalista debía conformarse con colectar una rama con varias hojas y flores. Para impedir el daño de los ejemplares, el joven naturalista debería llevar consigo un balde grande con varias hojas de papel y diarios viejos para conservarlas de la mejor manera. Una vez en su escritorio, el joven debía secar las muestras con papel poroso para evitar la formación de organismos que llegaran a deteriorar el ejemplar (Apolinar María, 1914d, pp. 266-267).

Hacia el mes de noviembre de 1914, un mes después de la divulgación de las instrucciones de recolección, el Hermano Apolinar María (1914e, pp. 280-194) publicó una nueva entrega sobre las indicaciones necesarias para los jóvenes naturalistas en el momento de colectar insectos coleópteros o lepidópteros. Al ser abundantes durante la época de invierno, la captura de los coleópteros debía realizarse durante estas épocas del año, generalmente se localizaban debajo de las deyecciones de los animales, debajo de los árboles, etc. El instrumento que era necesario usar para cazarlos podía elaborarse en casa con un alambre fuerte, al cual se fijaba a una red hecha de tela. Para matarlos, afirma el Hermano Apolinar, era suficiente con guardarlos en un frasco que contuviera un poco de aserrín empapado con bencina, gasolina y hasta petróleo; tiempo después, los insectos muertos se envolvían en papeles luego de haber encogido bien las patas apretándolas contra el cuerpo. Antes de empacar los animales, y para evitar que se corrompieran en las cajas, era menester dejarlos secar, para tal efecto se exponían al sol los paquetes que contenían los insectos; así, luego de ser preparados se les conservaba en cajas bien cerradas con un poco de alcanfor. El cumplimiento de estas instrucciones redundaba en el éxito de la colección y de la práctica del joven naturalista, por esta razón, era necesario seguir de manera rigurosa los pasos sugeridos.

Por su parte, en la recolección de los lepidópteros era necesario conocer bien sus características para tener una colección variada. A propósito, el Hermano Apolinar María presentó los rasgos generales de los lepidópteros y la taxonomía 
en la que podían ubicarse diversos ejemplares. A la vez, sugirió el diseño de una red (también casera) que contara con un diámetro más grande, cuya tela estuviera empapada de tajadas de plátano o guarapo viejo para atraer la atención de los lepidópteros. Para matarlas bastaba con apretar el pecho del insecto con unas pinzas o con un alfiler, después de muertos también debían dejarse secar. Si el interés del joven naturalista era colectar reptiles, entonces el Hermano Apolinar sugirió que tras su captura debían untarse con alcohol impotable, para luego abrirlos desde la garganta hasta el origen de la cola: "esta manera de operar, aunque no sea lo que hay de más perfecto, facilita al joven naturalista el trabajo de quitarle el cuero al animalito" (Apolinar María, 1914e, p. 288).

La captura y conservación de las aves, según el Hermano Apolinar, tenía un trabajo mayor. Así, una vez asesinada con una escopeta debía recogerse con rapidez para que las plumas no se mancharan; enseguida, se cubría la herida con un algodón y se introducía una pelota de algodón en el pico. Mientras tanto, el naturalista debía anotar datos como color del ojo, del pico, de las patas, de las partes desnudas de la cabeza y cuello; también debía medir la longitud del cuello, del cuerpo desde el cuello hasta la cola, desde los hombros hasta la base de los muslos y la distancia entre la punta de las alas y la punta de la cola (Apolinar María, 1914e, pp. 290-291). Al tener en cuenta todas estas variables, el aficionado educaría su mirada y recurriría el campo de lo visible. Con ello, para tener una colección ornitológica, se mostró innecesario tener a las aves empajadas, apenas era suficiente con incluir un rótulo en el que se mencionaran el lugar y fecha de captura, el nombre técnico o nombres vulgares, la época y lugar de nidificación, el número de huevos puestos y la alimentación de la especie. En la entrega de julio de 1915, el Hermano Apolinar (1915a, 1915b) se aseguró que los colectores conocieran el listado de nombres que tipificaron la taxonomía de las aves y sus respectivas características, razón por la que publicó un extenso listado con tal información para que el lector supiera clasificar la muestra encontrada. Esto es, para que el lector conociera el lenguaje universal al cual debía traducir las muestras colectadas.

Como puede notarse estas instrucciones, al detallar los procedimientos que debían efectuarse, hicieron uso de un lenguaje coloquial para tener un mayor acercamiento con el público lector aficionado incapaz de comprender explicaciones técnicas. Términos como "cajita", "animalito" y "descarnar", así como el ejercicio de nombrar las especies con nombres vulgares, de modo que los lectores 
reconocieran las clases de animales a los que se refería el autor, fueron algunas de las estrategias retóricas empleadas por el Hermano Apolinar para "pedagogizar" al lector inexperto y garantizar la correcta recolección de ejemplares que pudiera aumentar las muestras del Museo de La Salle. De ahí que hacia 1917 el Hermano Apolinar decidiera instruir a lector con la elaboración de un extenso listado con los nombres vulgares adjudicados a diversas especies de aves con su respectivo nombre científico. Este ejercicio de traducción les daría herramientas a los lectores para que, una vez realizada la captura del ave, lograran ubicarla dentro del listado de especies conocidas y clasificadas, o determinarla como novedad, para lo que sería necesario enviar la muestra a la Sociedad y esta comprobara la validez de tal descubrimiento. Con ello, la sociedad funcionaba como un centro de control cuya autoridad científica contaba con la potestad de determinar las novedades en el campo de las ciencias naturales en el país. Desde luego, en muchas ocasiones acudían al juicio de ornitólogos y botánicos extranjeros (generalmente estadounidenses) para respaldar sus apreciaciones.

Para terminar, resta decir que el presente escrito permitió trazar las imágenes de ciencia expuestas en el Boletín de Ciencias Naturales del Instituto de La Salle, llamado después la Sociedad Colombiana de Ciencias Naturales, de manera que lograra evidenciar la coexistencia del proyecto ilustrado, centrado en la observación y ordenamiento de la naturaleza, con las ciencias experimentales que tenían lugar en el laboratorio químico. En este mismo orden, se mostró la importancia de los viajes en la concepción de la práctica científica y la relación que sostuvieron los socios con sus lectores a partir de la correspondencia y las extensas publicaciones que con las que procuró instruirlos.

Referencias

Abadía, G. (1913). Excursión científica. Boletin de Ciencias Naturales del Instituto de La Salle, 1(2), pp. 58-62.

Apolinar María. (1913). Sección de botánica. Estudio comparativo entre la flora francesa y la flora de la sabana. Boletín de Ciencias Naturales del Instituto de La Salle, 1(1), pp. 9-11.

Apolinar María. (1914a). Sección zoológica. El cernícalo. Boletin de Ciencias Naturales del Instituto de La Salle, 2(4), pp. 100-109. 
Apolinar María. (1914b). Apuntes entomológicos. Boletín de Ciencias Naturales del Instituto de La Salle, 2(2), pp. 14-17.

Apolinar María. (1914c). Sección de mineralogía. Minerales de Colombia, en especial de la cordillera oriental. Boletin de Ciencias Naturales del Instituto de La Salle, 2(4), pp. 125.

Apolinar María. (1914d). Indicaciones para los jóvenes naturalistas. Boletín de Ciencias Naturales del Instituto de La Salle, 2(9), pp. 266-267.

Apolinar María. (1914e). Indicaciones para los jóvenes naturalistas. Boletín de Ciencias Naturales del Instituto de La Salle, 2(10), pp. 280-294.

Apolinar María. (1915a). El ornitologista colombiano. Boletín de Ciencias Naturales del Instituto de La Salle, 3(6), pp. 82-90.

Apolinar María. (1915b). El ornitologista colombiano. Boletin de Ciencias Naturales del Instituto de La Salle, 3(9), pp. 134-136.

Apolinar María. (1924). Sección de ciencias aplicadas. Las chinches. Boletín de la Sociedad Colombiana de Ciencias Naturales, 11(74), pp. 36-39.

Bonitto, G. (1916). Sección oficial. Boletín de Ciencias Naturales del Instituto de La Salle, 3(33), pp. 113-117.

Cadavid, F. (1918). Sección oficial. Boletín de Ciencias Naturales del Instituto de La Salle, 6(52-54), pp. 41-46.

Castro Gómez, S. (2005). La hybris del punto cero. Ciencia, raza e ilustración en la Nueva Granada 1750-1816. Bogotá: Editorial Pontificia Universidad Javeriana. Castro Gómez, S. (2010). Crítica de la razón latinoamericana. Bogotá: Editorial Pontificia Universidad Javeriana.

Cristancho, M. (1918). Sección antropológica. Los indios Tunebos. Boletín de Ciencias Naturales del Instituto de La Salle, 6(49-50), pp. 25-32.

De La Torre y Thorne, F. (1915). Direcciones para la caza y cría de los heterópteros acuátiles. Boletín de Ciencias Naturales del Instituto de La Salle, 3(7), pp. 101-112.

Dussel, E. (1980). Filosofía de la liberación. Bogotá: USTA.

Ferreira, M. (1913a). Riquezas minerales de Colombia. Boletín de Ciencias Naturales del Instituto de La Salle, 1(4), pp. 115-117

Ferreira, M. (1913b). El platino. Boletin de Ciencias Naturales del Instituto de La Salle, 1(5), pp. 129-132. 
Foucault, M. (2000). Las palabras y las cosas. Buenos Aires: Siglo veintiuno editores. Gaell, R. (1915). El sueño del naturalista. Boletin de Ciencias Naturales del Instituto de La Salle, 3(2), pp. 29.

Herrera, D. (1992). El futuro de la filosofía en Colombia. G. Marquínez Argote (Comp.), La filosofía en Colombia. Historia de las Ideas. Bogotá: Editorial El Búho.

López López, H. (1989). Contribución de los lasallistas a las ciencias naturales en Colombia. Bogotá: Fondo Fen.

Lora, E. (1917). Discurso leído en la velada científica del 7 de Septiembre de 1916. Boletin de Ciencias Naturales del Instituto de La Salle, 5(36), pp. 14.

Manrique, J. (1919). Sección no oficial. Boletin de Ciencias Naturales del Instituto de La Salle, 7(56-58), p. 87

Marquínez Argote, G. (1981). ¿Qué es eso de filosofía latinoamericana? Bogotá: El Búho.

Miró Quesada, F. (1974). Despertar y proyecto de filosofar latinoamericano. México D.F.: F.C.E.

Nieto, M. (2006). Remedios para el imperio: historia natural y la apropiación del Nuevo Mundo. Bogotá: ICANH.

Nieto, M. (2007). Orden Natural y Orden Social: ciencia y politica en el Semanario del Nuevo Reyno de Granada. Bogotá: Consejo Superior de Investigaciones Científicas.

Nietzsche, F. (2009). La genealogía de la moral. Madrid: Alianza Editorial.

Obregón Torres, D. (1992). Sociedades cientificas en Colombia: la invención de una tradición 1859-1936. Bogotá: Banco de la República.

Ortega y Gasset, J. (1981). El tema de nuestro tiempo. Madrid: Alianza Editorial. Palacios, M. (2009). El café en Colombia, 1850-1970. Una historia económica, social y politica. México D.F.: El Colegio de México.

Quintero, C. (2012). Birds of Empire, Birds of Nation. A History of Science, Economy, and Conservation in United States-Colombia Relations. Bogotá: Ediciones Uniandes.

Quintero, M. (1928). Sección oficial. Boletín de la Sociedad Colombiana de Ciencias Naturales, 16(97), pp. 130-132. 
Restrepo, O. (1996). De efemérides y tradiciones. La historia de la ciencia en la Revista de la Academia Colombiana de Ciencias Exactas, Físicas y Naturales, 1936-1995. Revista de la Academia Colombiana de Ciencias Exactas, Fisicas y Naturales, 20(77), pp. 269-280.

Rochereau, E. (1914a) Sección de antropología. Los indios tunebos. Boletín de Ciencias Naturales del Instituto de La Salle, 2(4), p. 97.

Rochereau, E. (1914b). Sección de antropología. Los indios tunebos. Boletin de Ciencias Naturales del Instituto de La Salle, 2(7), pp. 135-141

Rochereau, E. (1914c). Sección de antropología. Los indios tunebos. Boletín de Ciencias Naturales del Instituto de La Salle, 2(7), pp. 195-197.

Rochereau, E. (1924a). Entre los indios del alto Arauca. 8 apuntes de un padre eudista. Boletin de Ciencias Naturales del Instituto de La Salle, 12(77), pp. 123-128.

Rochereau, E. (1924b). Entre los indios del alto Arauca. Boletín de Ciencias $\mathrm{Na-}$ turales del Instituto de La Salle, 12(78), pp. 161-163.

Rochereau, E. (1925). Entre los indios del Alto Arauca. Boletin de Ciencias Naturales del Instituto de La Salle, 13(80), pp. 37-39.

Salazar Ramos, R. (1995). El ejercicio de la filosofía como arqueología. Dissens. Revista Internacional del Pensamiento Latinoamericano, 1, pp. 43-50.

Saldarriaga, O \& Saenz, J. (1997). Mirar la infancia: pedagogia, moral y modernidad en Colombia, 1903-1946. Bogotá: Colciencias/Ediciones Unidandes/ Ediciones Foro Nacional por Colombia.

Saldarriaga, O. (2003). Del oficio de maestro: prácticas y teorías de la pedagogía moderna en Colombia. Bogotá: Cooperativa Editorial Magisterio/Grupo Historia de la Práctica Pedagógica.

Silva, R. Los ilustrados de Nueva Granada, 1760-1808: genealogía de una comunidad de interpretación. Medellín: EAFIT.

Tovar, L. (2001). La filosofía colombiana a fines del siglo XX. Ideas y Valores, 50(117), pp. 107-118.

Velásquez, R. (1916). Sección de antropología. Boletín de Ciencias Naturales del Instituto de La Salle, 4(34), pp. 131-137.

Zea, L. (1976). El pensamiento latinoamericano. Barcelona: Ariel. 